\title{
Drying behavior of microwave dried ginger and their energy consumption
}

\author{
Chandra Prakash ${ }^{1}$ and A. K. Srivastava ${ }^{2}$ \\ ${ }^{1}$ Baba Farid Institute of Technology, Dehradun, Uttarakhand, India. \\ ${ }^{2}$ Department of Post Harvest Engineering and Technology, AMU, Aligarh (UP) India.
}

\begin{abstract}
Fresh ginger slice was dehydrated in a microwave oven to study the drying behavior and energy consumption of dried products. The ginger was dried at different microwave power and slice thickness. Moisture content as well as the drying time both decreased with a decrease in slice thickness in most of the cases. In majority of the cases, the Henderson and Pabis model was found to fit the best to the experimental data. The linear model for moisture content was found significant at $p \leq 0.01$. The regression model for the energy consumption was significant at $p \leq 0.01$.

Keyword: Drying behavior, Microwave wave, Page's model, Energy consumption
\end{abstract}

The removal of moisture from food products is one of the oldest methods of preservation. By reducing the water content of food products to very low levels, the likelihood of microbial deterioration is minimized and the rates of other deteriorative reactions are reduced significantly. In addition to preservation, dehydration reduces mass and volume of product by a significant amount and improves the efficiency of their transportation and storage. Often, the dehydration of food results in a product that is more convenient in use. Ginger is herbaceous perennial plant known as Zingiber officinale (Rosc.), which belongs to the order scitamenase and the family, zingiberacease. It is a tropical herb extensively grown for its pungently aromatic underground stem or rhizome which is an important export crop valued for its powder, oil and oleoresin (NEPC, 1999). The ginger is used as spice in culinary, beverage, confectionery, pharmaceutical and perfumery industries.

Dry ginger contains 1-3\% essential oil, 5-10 $\%$ oleoresin, $50-55 \%$ starch and 7-12\% moisture, with protein, fiber; fat and ash as its other constituents (Ebwele and Jimoh, 1981). Ginger contains moderate amounts of magnesium, calcium, protein, calcium, iron, sodium, potassium and phosphorus. Together they act as are medicine for muscle spasms, depression, hypertension, muscle weakness, convulsions, confusion, personality changes, nausea and gastrointestinal disorders. The high level of potassium in ginger protects the body from bone fragility, paralysis, sterility, muscle weakness, kidney damage and damage to the heart. Ginger also has a high content of antioxidants which means it also has anti-inflammatory properties. Ginger is a seasonal product but it is used extensively in many food herbal medicine preparations. Hence, dried ginger or ginger powder is used in large quantity during off-season.

Okafor and Okafor (2007) studied the effect of pricking and sun drying on colour retention of Nigerian yellow bark ginger. The interior colour of fresh ginger surface was $24 \%$ lighter than the skin surface colour. Drying decreased the external surface colour by $12.5 \%$, pricking darkened the interior surface of ginger by $7.2 \%$ and $2.6 \%$ respectively for black and gray backgrounds respectively.

Balladin et al. (1996) used a wire basket dryer $(1.8 \mathrm{~m} \times 0.9 \mathrm{~m} \times 0.2 \mathrm{~m})$ to dry sliced $(0.15 \mathrm{~cm})$ West Indian ginger rhizome to a moisture content of $10.2 \%$ $(\mathrm{db})$ over a 3 day period. The optimum charge size was $14.97 \mathrm{~kg}$, with a packing density of $462.04 \mathrm{~kg} \mathrm{~m}^{-3}$ and a specific drying rate of $0.446 \mathrm{~h}^{-1}$. The quantities of the main pungent principles extracted from fresh, nonsteam-distilled solar-dried and steam-distilled solardried ginger rhizomes showed increases of $0.068,0.46$ and $0.67 \mathrm{~g} /$ per $100 \mathrm{~g}(\mathrm{db})$, respectively, with a decrease in the oleoresin quality (reflected in pungency profile) of the same order.

In microwave drying, electromagnetic energy is directly converted into kinetic energy of the water molecules, thus generating heat within the product, and energy transport is not affected by conductivity barriers, especially in high viscosity or lumpy materials (Bouraoui et al., 1994; Kiranoudis et al., 1997; Kudra 
and Majumdar, 2002). The amount of heat generated depends on the strength of the electromagnetic field and the dielectric properties of the material being heated (Gracia et al., 1992). The energy absorbed by the material initiate moisture evaporation, which increases internal pressure and drives the moisture from the interior to the surface. Microwave drying has several advantages, such as uniform energy and high thermal conductivity to the inner sides of the material, space utilization, sanitation, energy saving, fast startup and shutdown conditions, compared to other drying methods applied. Microwave drying reduces the drying time, thereby prevents the food from enzymatic decomposing (Decareau, 1985; Barbosa and Vega, 1996). Improved rehydration and textural properties due to puffing effects as a result of internal expansion of the microstructure (Raghavan and Silveria, 2001; Lin et al., 1998), are also the major advantages of microwave drying.

Microwave causes less nutrient loss than conventional methods. This is substantiated by available studies of nutrient loss in microwaved foods, which conclude that nutrient loss is actually more severe in conventional cooking (Flein, 1989; Lassen et al., 1995; Fumio et al., 1998; Vallejo et al., 2003). Raghavan et al.,(2004) studied the effect of microwaveassisted convective drying on the partial dried (osmotically dehydrated) cranberries. Quality evaluation was performed on all samples, including sensory evaluation (appearance and taste), texture, colour, water activity, and rehydration ratio. Microwave-assisted to hot air drying rate ratios increased as the moisture content decreased.

Askari et al., (2006) investigated the effect of coating, hot-air and microwave drying on the texture, microstructure and rehydration characteristics of Golden Delicious apple slices $(22 \mathrm{~mm}$ diameter, $4 \mathrm{~mm}$ thickness). Apple slices were blanched in hot water $\left(80^{\circ} \mathrm{C}, 1 \mathrm{~min}\right)$ and coated with a starch (suspension), pectin and carboxymethylcellulose solution $(20 \mathrm{~g} / \mathrm{l})$ with and without $\mathrm{CaCl}_{2}(10 \mathrm{~g} / \mathrm{l})$. The study showed that the type of coating material has a significant effect on textural quality such as texture strength. Starch (in suspension form) and pectin with $\mathrm{CaCl}_{2}$ had the best quality characteristics (more porosity, less apparent density and more rehydration capacity). Also, microwave treatment improved the rehydration capacity and decreased the texture firmness which was due to rupture and deformation caused in cell walls during the treatment.

With increasing demand of processing, pharmaceutical industries as well consumers for hygienic and superior quality end products, a viable new and innovative dehydration technology should not only and represent higher efficiency a lower drying cost but should have little bit or no loss in sensorial attributes of the dried products. The objective of this research was to investigate the effect of microwave power and slice thickness on drying behavior and quality attributes viz. moisture content, rehydration ratio, bulk density, apparent density and total colour change. The outcome or finding of this study will provide reference data on drying of ginger by microwave drying for further research and development of practical production processes.

\section{Materials and methods}

Raw materials: Fresh ginger of unknown variety was procured from the local market and brought to the laboratory. For the study, rhizomes of light brown colour, free from spots, blemishes and shriveling, and having shiny surface, were picked up.

Experimental Setup: Adomestic kitchen microwave oven of Kenstar- Ken Chef, Model: MO- 9760A was used. The microwave has an input power of $1200 \mathrm{~W} \pm 5$ $\%$, and output power of $800 \mathrm{~W}$. The overall dimension of the microwave oven is $52 \mathrm{~cm} \times 27 \mathrm{~cm} \times 23 \mathrm{~cm}$ and internal chamber has a dimension of $32 \times \mathrm{cm} \times 30 \mathrm{~cm} \times$ $21 \mathrm{~cm}$. It has 5 adjustable power options and a timer. It is equipped with a magnetron, operates at a frequency of $2450 \mathrm{MHz}$, to convert electricity to microwave, a fan, and a centrally mounted turn-table.

Experimental Procedure: Fresh ginger rhizomes were peeled and cut in to slices of different thicknesses viz. 2.0, 4.0 and $6.0 \mathrm{~mm}$. For each experiment, approximately $100 \mathrm{~g}$ accurately weight sample of graded ginger slices was evenly spread over the perforated glass plate in the microwave heating chamber. Then, microwave was switched-on and desired microwave power was maintained by adjusting variac. The samples were periodically weighed to note the weight loss. For this, the microwave was switchedoff. Glass plate along with the sample was weighed on 
an electronic balance. The sample was subjected to further drying in similar way as described above. Samples were dried to their constant weight for a given level of thickness and microwave power. The constant weight was considered when two consecutive readings of sample's weight obtained were the same.

The dried sample was then kept inside a desiccator for cooling. When the temperature of the sample lowered to normal, it was packed in the LDPE pouches (100 gauges) and heat sealed. These dried ginger slices were then utilized further for the determination of various properties. The energy consumption in the drying was measured by connecting an electronic wattmeter in series. The electric supply to the experimental set up was controlled using a servo voltage stabilizer.

Experimental Design: The independent variables of microwave drying experiments were microwave power and slice thickness. The levels of these independent variables were selected by applying Central Composite Design (CCD). The CCD suits for fitting a quadratic surface, which usually works well for process optimization. Lower and higher levels of both the independent variables were chosen on the basis of preliminary trials which showed that microwave power higher than $500 \mathrm{~W}$ was too high for the drying purpose, as the sample underwent cooking rather than drying and also there was high occurrence of burning of the samples. Also, the microwave power below $100 \mathrm{~W}$ prolonged drying too much and yielded product of higher moisture content. A thickness range of $2-6 \mathrm{~mm}$ was selected in combination with the microwave power range of 100-500 $\mathrm{W}$ to study their effects on the various properties of the fresh dried ginger slices.

The CCD, for a two factor response, comprises of following three parts. Its pictorial representation is given in Fig. 1.

1. 5 central points $(0,0)$ are at center.

2. The 4 factorial points $(-1,-1) ;(1,-1) ;(-1,1)$ and $(1$, 1).

3. The 4 axial points $(-\alpha, 0) ;(\alpha, 0) ;(0,-\alpha)$ and $(0, \alpha)$ are included to form a CCD. This distance ' $\alpha$ ' is measured in terms of coded factor levels and may be chosen from a variety of options for alpha; i.e.
- Rotatable $\left(\alpha=2^{1 / 2} ; \mathrm{k}<5\right)$, where $\mathrm{k}$ is number of factors

- $\operatorname{Spherical}(\alpha=\sqrt{ } \mathrm{k})$

- Orthogonal Quadratic ( $\alpha$ value allows each term to be estimated independently of the blocks)

- Practical $\left(\alpha=k^{1 / 4} ; \mathrm{k}>5\right)$

- Face Centered $(\alpha=1)$

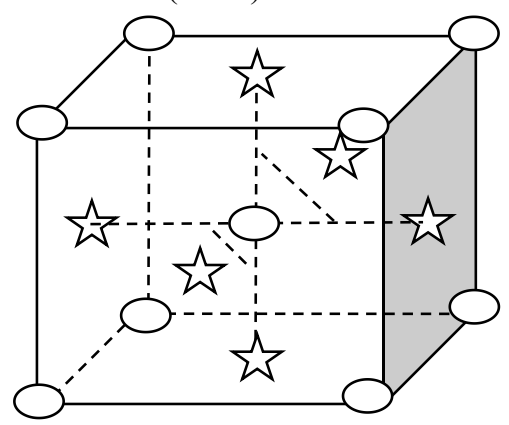

Fig. 1: Central composite cube showing various

\section{design points}

Since in face centered, the value for $\alpha$ is same as coded factor so the axial points lies on the face of the cube so formed, enabling to run the experiments in the range of selected levels of independent variables.

Statistical Analysis and Process Optimization: Using the experimental plan as described in the previous Section, altogether 21 experiments were conducted. Response surface methodology (RSM) was applied to various responses (viz. moisture content, rehydration ratio, bulk density, apparent density, total colour change, energy consumption and drying time) using design expert 7.1.6 software.

Response surface are represented by first order, second order or higher order, multiple linear/ polynomial regression models. For two independent variables (coded as $\mathrm{X}_{1}$ and $\mathrm{X}_{2}$ ), the first order linear regression model is

$\mathrm{Y}=\beta_{\mathrm{o}}+\beta_{1} \mathrm{X}_{1}+\beta_{2} \mathrm{X}_{2}$

and second order polynomial model is

$Y=\beta_{0}+\beta_{1} X_{1}+\beta_{2} X_{2}+\beta_{11} X_{2}^{2}+\beta_{22} X_{2}^{2}+\beta_{12} X_{1} X_{2} \ldots$ 
Where,

$\mathrm{Y}$ is any response variable and $\beta$ 's are coefficients of model terms.

In the present study adequacy of any regression model for fitting experimental results for any response was checked by adding interaction term $\left(\mathrm{X}_{1} \mathrm{X}_{2}\right.$ term) to the first order model followed by adding second order terms and so on, until the added term showed a non-significant improvement in adequacy of model. This manual method, for improving adequacy, is available in design expert 7.1.6 software.

In the response surface plotting the values of the dependent variables are represented as a three dimensional surface. The values of the dependent variable for any two values of independent variables can be determined from the plot. The graph is drawn on the basis of mathematical relationship given in equation (2) as.

$$
\begin{array}{r}
\mathrm{X}_{1}^{\text {opt. }}=\frac{2 \beta_{1} \beta_{22}-\beta_{2} \beta_{12}}{\beta_{12}^{2}-4 \beta_{11} \beta_{22}} \\
\mathrm{X}_{2}^{\text {opt. }}=\frac{2 \beta_{2} \beta_{11}-\beta_{1} \beta_{12}}{\beta_{12}^{2}-4 \beta_{11} \beta_{22}}
\end{array}
$$

The value of the response function under this condition is

$$
\mathrm{Y}^{\mathrm{opt.}}=\beta_{0}+\frac{\beta_{1} \mathrm{X}_{1}^{\mathrm{opt} .}}{2}+\frac{\beta_{2} \mathrm{X}_{2}^{\mathrm{opt} .}}{2}
$$

The overall optimization was done by choosing a desired goal for each factor and response from the possible goals, viz., maximize, target, within range, none (for response only) and set to a value (factors only).

These goals were then combined into an overall desirability function. In the desirability objective function $\mathrm{D}(x)$, each response was assigned an importance relative to the other responses (Anon, 2007). Importance varies from the least importance relative to the most important $(+++++)$ a value of 5 . In the present study the importance was set to 3 pluses $(+++)$ for most of the responses except rehydration ratio and moisture content for which the weightage were assigned as 5 pluses and 4 pluses, respectively, taking into account there importance in overall quality of dehydrated ginger. For the different importance value the desirability function given as:

$$
D(x)=\left(d_{1}^{r_{1}} \times d_{2}^{r_{2}} \times \ldots \ldots \ldots \times d_{n}^{r_{m}}\right)^{\frac{1}{\sum_{i=1}^{m} r_{i}}}
$$

Where $\mathrm{n}$ is the number of response in the measure and $d_{i} s$ are value according which goals for each response was set and $\mathrm{m}$ is the importance assigned to any response, $\mathrm{m}$, ranged between 1 and 5 .

\section{Analysis of Sample}

Moisture Content: Moisture content of ginger was determined by hot air oven method as recommended by Ranganna (1986) for volatile compounds containing products. Moisture content of samples was determined using following formula:

Moisture content (\%, dry basis)

$$
=\frac{\text { Loss in weight of samples }}{\text { Final (bone dry) weight of samples }} \times 100 \text {. }
$$

\section{Moisture ratio}

Moisture ratio $(M R)=\frac{X_{n}-X_{e}}{X_{o}-X_{e}}$ (in fraction)

Where, $X_{0}, X_{n}$, and $X_{e}$ are moisture contents of sample ( $\mathrm{g} / \mathrm{g}$ of dry matter) at the beginning of drying, at any time $\mathrm{t}=\mathrm{n}$ and at equilibrium state, respectively. Since all the samples were dried to their dynamic equilibrium state, $\mathrm{X}_{\mathrm{e}}$ is the moisture content at the end of drying.

Energy Consumption: The energy consumption was calculated by the following formula as suggested by Yongsawatdigul and Gunasekaran (1996) for drying efficiency and later termed as energy consumption by Changrue (2006).

Energy consumption $(\mathrm{MJ} / \mathrm{kg})$

$$
=\frac{\mathrm{t}_{\mathrm{ON}} \times \mathrm{P} \times\left(1-\mathrm{X}_{\mathrm{f}}\right) \times 10^{-6}}{\mathrm{~m}_{\mathrm{i}} \times\left(\mathrm{X}_{\mathrm{o}}-\mathrm{X}_{\mathrm{f}}\right)}
$$

Where, 
$t_{O N}$ is total power-on time (s), $\mathrm{P}$ is microwave input power $(\mathrm{W}), \mathrm{m}_{\mathrm{i}}$ is initial mass $(\mathrm{Kg}), \mathrm{X}_{\mathrm{o}}$ is initial moisture content (fraction), and $\mathrm{X}_{\mathrm{f}}$ is final moisture content (fraction).

Table 1: Coded and actual values of factors in microwave drying experiments

\begin{tabular}{|c|c|c|c|c|c|}
\hline S.No. & Point type & Coded value & $\begin{array}{l}\text { Microwave } \\
\text { power (W) }\end{array}$ & Thickness (mm) & No. of replications \\
\hline 1. & Factorial & $(-1,-1)$ & 100 & 2 & 2 \\
\hline 2. & Factorial & $(-1,1)$ & 100 & 6 & 2 \\
\hline 3. & Factorial & $(1,-1)$ & 500 & 2 & 2 \\
\hline 4. & Factorial & $(1,1)$ & 500 & 4 & 2 \\
\hline 5. & Center & $(0,0)$ & 300 & 4 & 2 \\
\hline 6. & Axial & $(-1,0)$ & 100 & 4 & 2 \\
\hline 7. & Axial & $(1,0)$ & 500 & 2 & 2 \\
\hline 8. & Axial & $(0,-1)$ & 300 & 6 & 2 \\
\hline 9. & Axial & $(0,1)$ & 300 & & 2 \\
\hline
\end{tabular}

\section{Results and discussion}

The effect of microwave power and slice thickness on drying behavior of ginger slices are discussed below:

Change in moisture content during drying: Fig. 2 to 4 represent drying curves at $100 \mathrm{~W}, 300 \mathrm{~W}$ and $500 \mathrm{~W}$ microwave power levels respectively for varied levels of thickness of ginger slices viz. $2.0 \mathrm{~mm}, 4.0 \mathrm{~mm}$ and $6.0 \mathrm{~mm}$. It is clearly evident from the figures that moisture content of samples decreased with the increase in drying time until they reached a constant value. The average calculated initial moisture contents of fresh sample was $378.8 \%$ (d.b.) worked out by backward calculation, using mass balance from final moisture content of dehydrated samples determined by hot air oven method, the reduction in moisture was faster during initial stage of drying as is evident by steeper slope of drying curves. However, as the drying proceeded the slope of curves became flatter and indicating slower drying. At a given microwave power level, the drying occurred relatively faster in samples having lower thickness. For example, at $500 \mathrm{~W}$ microwave power level, say after 30 min of drying the moisture contents of the samples of thickness $2 \mathrm{~mm}, 4$ $\mathrm{mm}$ and $6 \mathrm{~mm}$ were $49.0 \%, 66.3 \%$ and $127.0 \%(\mathrm{db})$, respectively.

This effect of thickness was due to the fact that when the thickness of the slices were more, the rate of moisture migration from core to the surface became slower resulting in slower rate of drying. Also, the intensity of microwave power at inner location of materials decreases with thickness, resulting in slower heating and consequently a lower drying rate. Thickness of slices also affected the final moisture content as well as the drying time and both decreased with a decrease in slice thickness in most of the cases. For example at 100 W power level the final moisture content of $2 \mathrm{~mm}, 4 \mathrm{~mm}$ and $6 \mathrm{~mm}$ slices were $6.9, \quad 8.3$ and $8.5 \% \quad(\mathrm{db})$ respectively and corresponding drying times were 250 , 270 and 280 minutes. The microwave power head pronounced effect on drying of ginger slices as is 
evident from the total drying time and final moisture content of the samples dried at various microwave power level. For example at $100 \mathrm{~W}, 300 \mathrm{~W}$, and $500 \mathrm{~W}$, power level the final moisture content of sample of $2 \mathrm{~mm}$ thickness were $6.9,6.3$, and $5.7 \% \quad(\mathrm{db})$ respectively and there corresponding drying time were 250,70 and $55 \mathrm{~min}$. Similarly for $4 \mathrm{~mm}$ thick sample the values were $8.3,7.7$, and $6.3 \%(\mathrm{db})$ respectively and corresponding time were 270,80 and $60 \mathrm{~min}$. this indicates that at higher microwave power level. Substantial reduction in drying time occurred whereas the reduction in moisture was not so much substantial.

Regression modeling of drying: Two most commonly used drying models (Brooker et al., 1974) namely Henderson \& Pabis and Page model, as given below, were tested for validation of drying data

Henderson and Pabis model

$$
\mathrm{M} \cdot \mathrm{R}=\mathrm{a}^{*} \exp (-\mathrm{kt})
$$

Page's model

$$
M \cdot R=\exp \left(-k t^{n}\right)
$$

Where,

M.R is moisture ratio

$\mathrm{t}=$ Time period, $\min$

$\mathrm{a}, \mathrm{n}$ and $\mathrm{k}$ are constants.

The models were fitted to the experimental data using $\Sigma$-Plot.

\section{Table 2: Anova for energy consumption}

Henderson and Pabis model: The drying constants ('a, $\&$ ' $k$ ') of the Henderson and Pabis models for various thickness and microwave power combinations are presented in Fig. 5 to 7 . The coefficient of determination ( $\mathrm{R}^{2}$ value) ranged between 0.978 and 0.936. As is evident from figures, in majority of the cases, the Henderson \& Pabis model was found to fitting the best to the experimental data.

Page's model: Fitting of non linear Page model to the experimental data yielded values of constant ' $\mathrm{k}$ ' and ' $\mathrm{n}$ ' as are reported in Figs. 5-7. The coefficient of determination the $\left(\mathrm{R}^{2}\right.$ values) ranged between $0.996 \&$ 0.819 . The Page model was found to fit better than the Henderson \& Pabis model in few cases viz. for $2 \mathrm{~mm}$ and $6 \mathrm{~mm}$ thick samples dried at $100 \mathrm{~W}$ microwave power, $2 \mathrm{~mm}$ sample dried at $300 \mathrm{~W}$ and $4 \mathrm{~mm}$ sample dried at $500 \mathrm{~W}$.

Energy Consumption: Energy Consumption depends on the factors like power of the applied microwave, time duration of exposure of the microwave, mass of the sample being dried, and initial and final moisture content.Table 2 shows that the regression model for the energy consumption was significant at $\mathrm{p} \leq .01$. Linear and quadratic terms of microwave power were also found to be significant at $\mathrm{p} \leq 0.01$ but only the linear term of thickness was significant (at $\mathrm{p} \leq 0.05$ ). The two factor interaction term of both the factors (microwave power and slice thickness) and quadratic term of thickness did not affect the drying efficiency significantly.

\begin{tabular}{|c|c|c|c|c|}
\hline Source & Sum of squares & Df & Mean square & F-value \\
\hline Model & 0.012 & 3 & $4.15 \times 10-3$ & $19.35^{* *}$ \\
\hline $\mathrm{X}_{1}$-microwave power & $2.69 \times 10-3$ & 1 & $2.70 \times 10-3$ & $12.57^{* *}$ \\
\hline $\mathrm{X}_{2}$ thickness & $1.87 \times 10-3$ & 1 & $1.87 \times 10-3$ & $8.69^{* *}$ \\
\hline $\mathrm{X}_{1}{ }^{2}$ & $7.9 \times 10-3$ & 1 & $7.89 \times 10-3$ & $36.80^{* *}$ \\
\hline Residual & $3.65 \times 10-3$ & 17 & $2.14 \times 10-3$ & 0.45 \\
\hline Lack of fit & $5.78 \times 10-4$ & 5 & $1.16 \times 10-3$ & \\
\hline Pure error & $3.07 \times 10-3$ & 12 & $2.56 \times 10-3$ & \\
\hline Significance: $* *(\mathrm{p} \leq 0.01) ;(\mathrm{p} \leq 0.05), \mathrm{R} 2=0.7735$ & \\
\hline
\end{tabular}



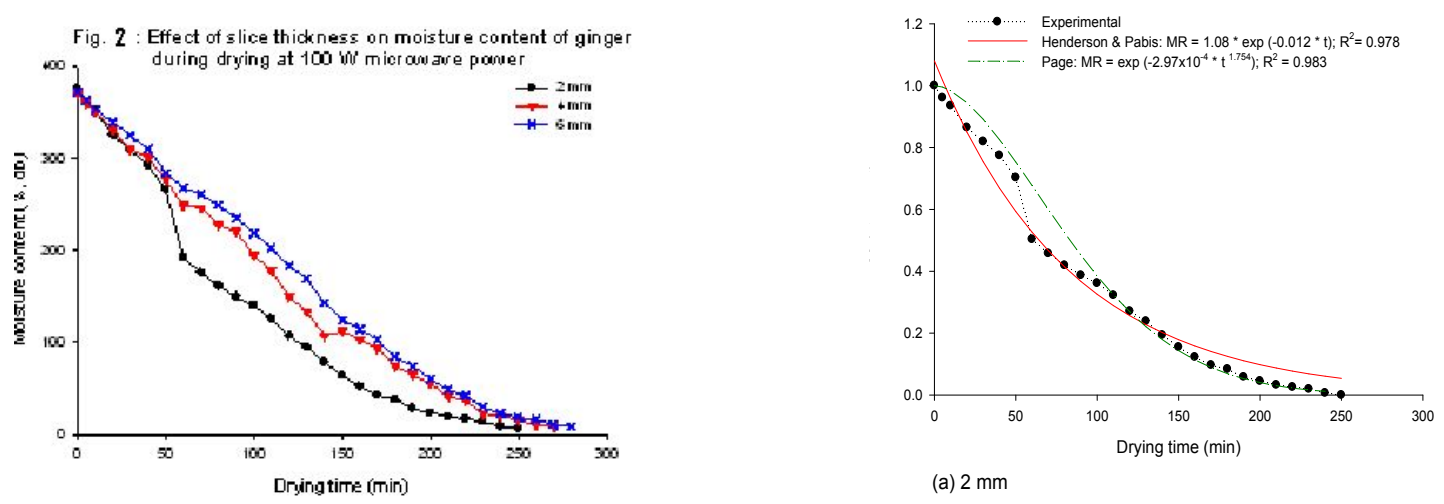

(a) $2 \mathrm{~mm}$
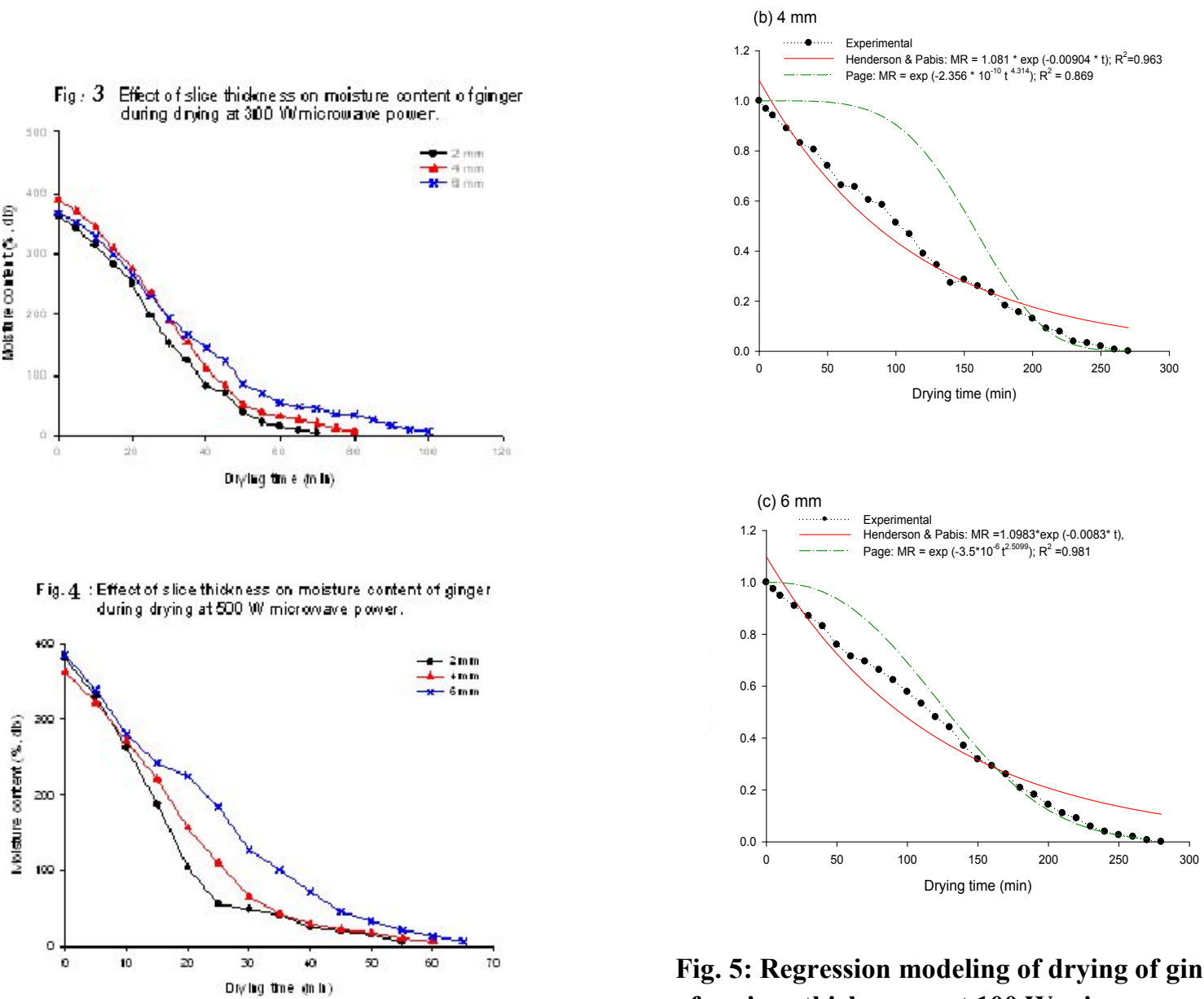

Fig. 5: Regression modeling of drying of ginger slices of various thicknesses at $100 \mathrm{~W}$ microwave power 

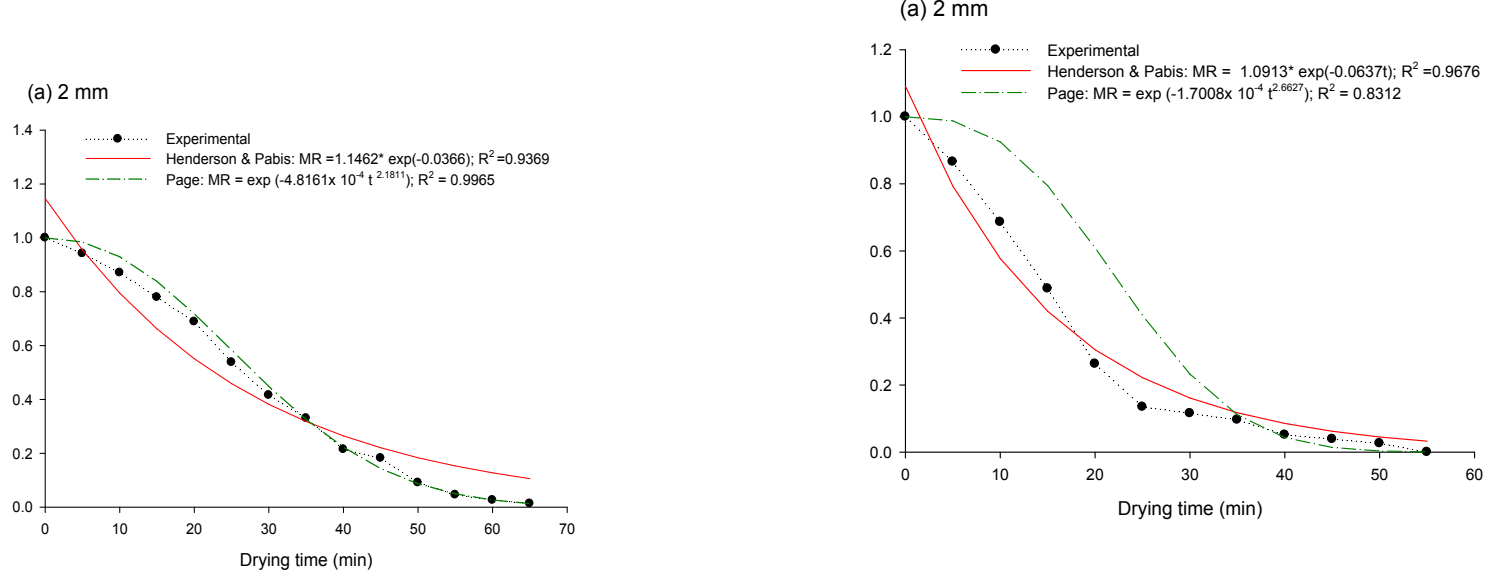

(b) $4 \mathrm{~mm}$

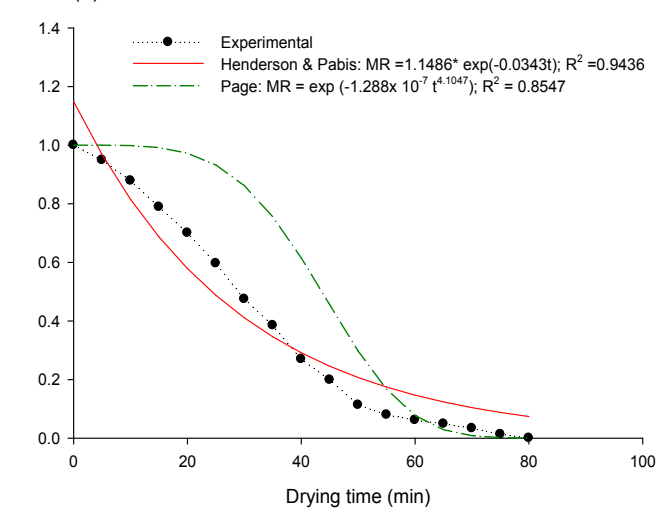

(c) $6 \mathrm{~mm}$

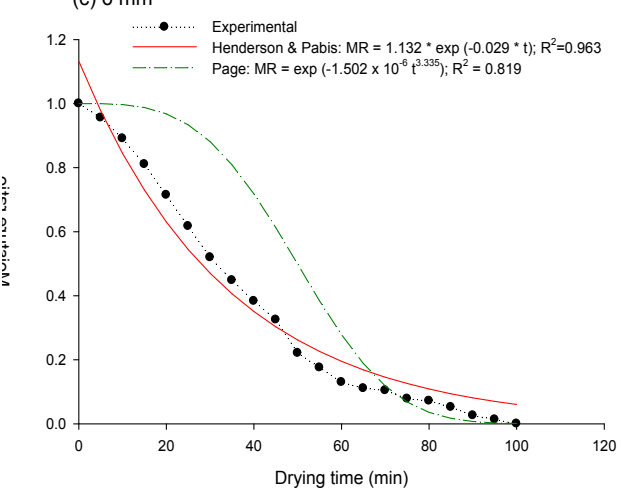

Fig. 6: Regression modeling of drying of ginger slices of various thicknesses at $300 \mathrm{~W}$ microwave power
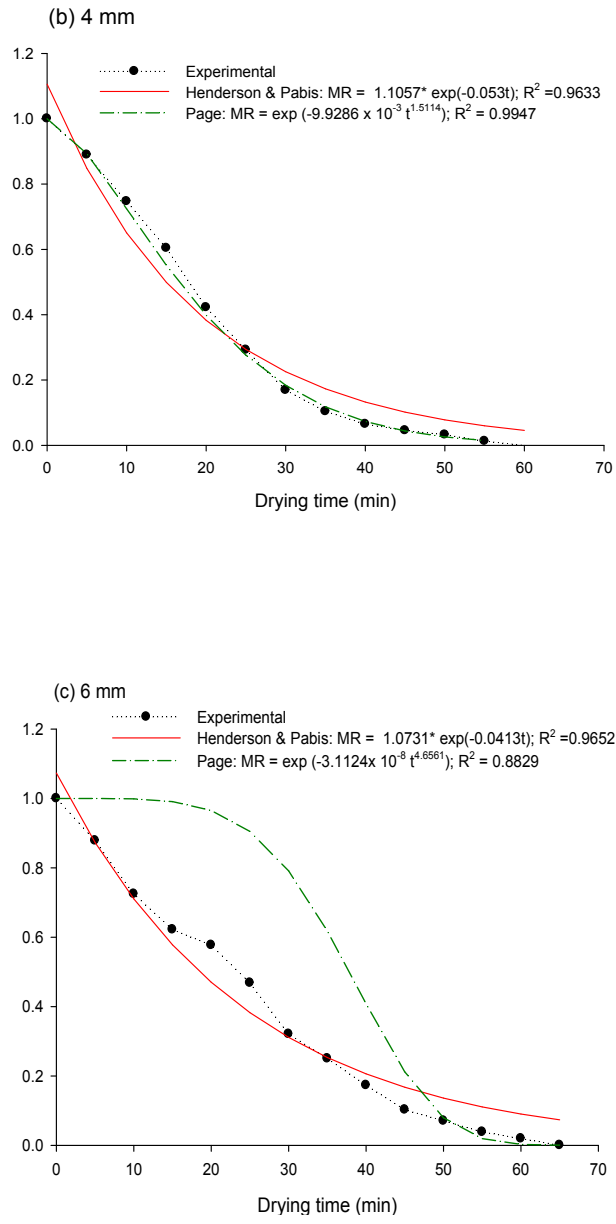

Fig. 7: Regression modeling of drying of ginger slices of various thicknesses at $500 \mathrm{~W}$ microwave power 
Although, the coefficient of determination $\left(\mathrm{R}^{2}\right)$ was not high, the quadratic model is acceptable because the "lack of fit" was not significant. The quadratic model, in coded terms, is as follow:

Energy Consumption $=0.13+0.015 * \mathbf{X}_{1}+0.012 * \mathbf{X}_{\mathbf{2}}$ $+0.039 * \mathbf{X}_{1}{ }^{2}$

Fig. 8 shows the contour plots and 3D response surface plots, depicting the influence of microwave power and slice thickness on the predicted values of response variable (energy consumption). Starting from the centre-point $(\mathrm{A}=300 \mathrm{~W}, \mathrm{~B}=4 \mathrm{~mm})$ value of 0.1323 $\mathrm{MJ} / \mathrm{kg}$, the energy consumption increased to 0.187 $\mathrm{MJ} / \mathrm{kg}$ when the microwave power was increased to 500 $\mathrm{W}$ and to $0.157 \mathrm{MJ} / \mathrm{kg}$ when microwave power was decreased to $100 \mathrm{~W}$. Hence, at both, higher and lower microwave powers the predicted values energy consumptions were higher than that at intermediate level (300W) of microwave power.
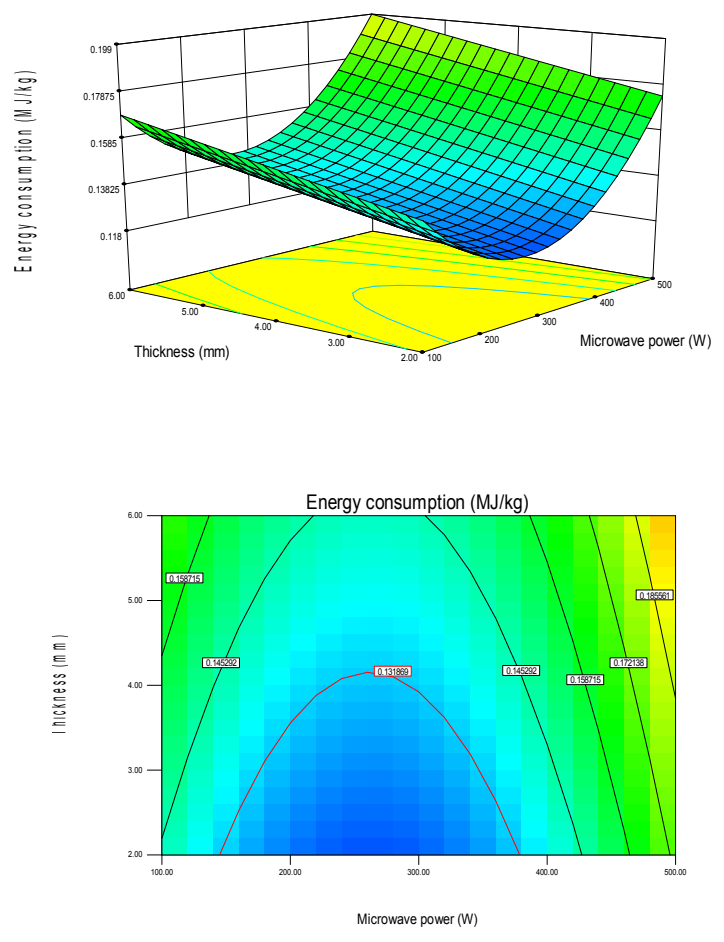

Fig. 8: Contour and Response surface plots showing the dependency of the energy consumption on microwavepower and slice thickness
However, from the center-point value, the energy consumption increased when the thickness increased and vice-versa. It is evident from the Fig. 8 that at $300 \mathrm{~W}$ and thicknesses of $2 \mathrm{~mm}$ and $6 \mathrm{~mm}$ the predicted values of energy consumptions was 0.120 and $0.149 \mathrm{MJ} / \mathrm{kg}$, respectively, whereas at $4 \mathrm{~mm}$ thickness it was $0.132 \mathrm{MJ} / \mathrm{kg}$. Similar trends have also been predicted at other microwave power levels with

respect to thickness. A lower value of energy consumption indicates that lower amount of heat (in MJ) is required to evaporate a unit quantity $(\mathrm{kg})$ of water. Therefore, the lowest value of energy consumption lies near $300 \mathrm{~W}$ microwave-power and $2 \mathrm{~mm}$ slicethickness. The 3D plot indicates that energy consumption varying linearly with thickness while it is varying non-linearly with microwave power.

Conclusions: The microwave power head pronounced effect on drying of ginger slices as is evident from the total drying time and final moisture content of the samples dried at various microwave power level. Thickness of slices also affected the final moisture content as well as the drying time and both decreased with a decrease in slice thickness in most of the cases. The Page model was found to fit better than the Henderson \& Pabis model in few cases viz. for $2 \mathrm{~mm}$ and $6 \mathrm{~mm}$ thick samples dried at $100 \mathrm{~W}$ microwave power, $2 \mathrm{~mm}$ sample dried at $300 \mathrm{~W}$ and $4 \mathrm{~mm}$ sample dried at $500 \mathrm{~W}$.The regression model for the energy consumption was significant at $\mathrm{p} \leq .01$. Linear and quadratic terms of microwave power were also found to be significant at $\mathrm{p} \leq 0.01$ but only the linear term of thickness was significant (at $\mathrm{p} \leq 0.05$ ). Although, the coefficient of determination $\left(\mathrm{R}^{2}\right)$ was not high, the quadratic model is acceptable because the "lack of fit" was not significant. The microwave drying of ginger slices at input microwave power of 300 and $500 \mathrm{~W}$ considerably reduced the drying time and yielded product which was superior in most of the quality parameters included in the present study.

\section{References}

1. Anon (2007). Stat-Ease Inc. Design Expert User's Guide. The Stat-Ease Inc.

2. Askari, G. R., Emam-Djomeh, Z., Mousavi, S. M., (2006). Effects of combined coating and 
microwave assisted hot-air drying on the texture, micro-structure and rehydration characteristics of apple slices.Food Sci. Tech. Intern. 12(1):39-46.

3. Balladin D. A., Chang Yen I., Mcgaw D. R., Headley, O. (1996). Solar drying of West Indian ginger (Zingiber officinale Roscoe) rhizome using a wire basket dryer. Renew. energy.7(4):409-418.

4. Barbosa-Canovas, G.V. and Vega-Mercado, H. (1996). Dehydration of Foods, $1^{\text {st }}$ ed; Chapman \& Hall, New York.

5. Bouraoui, M., Richard, P., Durance, T., (1994). Microwave and convective drying of potato slices.J. Food Process. Engg. 17:353-363.

6. Brooker, D.B., Bakker-Arkema, F. W., and Hall, C. W. (1974). Drying Cereal Grains. AVI Publishing Co. Inc., Connecticut, p: 265

7. Changrue(2006). Hybrid (osmotic, microwavevacuum) drying of strawberries and carrots. Ph.D. Thesis, Department of Bioresource Engineering McDonald Campus of McGill University Ste-Anne-de-Bellevue, Quebec, Canada

8. Decareau, R.V. (1985) Microwaves in the Food Processing Industry, 1st Ed; Academic Press Inc. (London) LTD. Orlando, FL.

9. Ebewele, R.O. and Jimoh, A.A. (1981). Feasibility study of Kaduna State ginger processing industry. Ahmadu Bello University Chemical Engineering Consultant.1-45, 50 -56, $63-80$.

10. Flein, B.P. (1989). Retention of nutrients in Microwave cooked foods. Bol. Asoc. Med. PR, 81(7): 277-279.

11. Fumio W., Katsuo A., Tomoyuki F., Masharhiro G., Miki H. And Yohihisa, N.(1998). Effects of Microwave Heating on the loss of vit-B $\mathrm{B}_{12}$ in foods.J. Agric. Food Chem. 46 (1): 206-210.

12. Gracia, A., Iglesias, O. and Roques, M. (1992). Microwave drying of agar gels. In: Mujumdar AS (Ed), Drying'92, Elsevier, New York, pp: 595-606

13. Kiranoudis, C. T., Tsami, E. and Maroulis, Z. (1997). Microwave vacuum drying kinetics of some fruits.Drying Technol. 15: 2421-2440.
14. Kudra, T. and Mujumdar, A. S. (2002). Advanced drying technologies; Marcel Dekker, New York.

15. Lassen A. and Ovesen, L. (1995). Nutritional effects of Microwave cooking.Nutri. Food Sci. 40(4): 8-100.

16. Lin, T. M., Durance, T. D. and Scaman, C. H. (1998). Characterization of vacuum microwave, air and freeze dried carrot slices.Food Res. Intern. 31:111-117.

17. NEPC (1999). Product profile of ginger. Nigerian Export Promotion Council B/K 312, Kumba, St, Wuse, Zone, II, Abuja, 1-6.

18. Okafor,G. I. and Okafor,J. N. (2007). Effects of pricking, sun-drying and sieving on Ginger (Zingiber officinale Roscoe) colour and powder.Nigerian Food J. 25 (1): 155-160.

19. Raghavan, G. S. V. and Silveira, A. M. (2001). Shrinkage Characteristics Of Strawberries Osmotically Dehydrated In Combination With Microwave Drying. Drying Tech. 19(2): 405414.

20. Raghavan G. S. V., Sunjka, P. S., Rennie, T. J. and Beaudry, C. (2004). MicrowaveConvective and Microwave-Vacuum Drying of Cranberries. Drying Tech. 22 (5): 1217-1231.

21. Ranganna, S. (1986). Handbook of Analysis and Quality Control for Fruits and Vegetables Products. Tata McGraw Hill Publishing Co. Ltd, New Delhi, 1986.

22. Yongsawatdigul, J. and Gunasekaran, S. (1996). Microwave-vacuum drying of cranberries: Part I. Energy use and efficiency. J. Food Process. Preserv. 20:121-143. 